NIST GCR 14-977

\title{
Disaster Resilience Workshop April 7, 2014
}

David R. Mizzen

Peter J. Vickery Applied Research Associates, Inc.

http://dx.doi.org/10.6028/NIST.GCR.14-977 
This publication was produced as part of contract SB1341-13-CN-0084 with the National Institute of Standards and Technology. The contents of this publication do not necessarily reflect the views or policies of the National Institute of Standards and Technology or the US Government. 
NIST GCR 14-977

\section{Disaster Resilience Workshop \\ April 7, 2014}

Prepared for

U.S. Department of Commerce

Engineering Laboratory

National Institute of Standards and Technology

Gaithersburg, MD 20899

By

David R. Mizzen

Peter J. Vickery

Applied Research Associates, Inc.

http://dx.doi.org/10.6028/NIST.GCR.14-977

June 2014

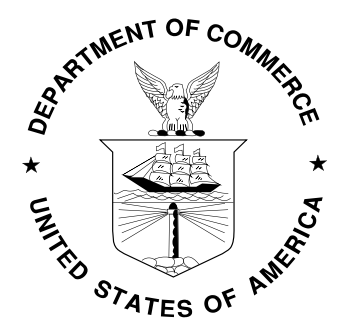

U.S. Department of Commerce Penny Pritzker, Secretary

National Institute of Standards and Technology Willie May, Acting Under Secretary of Commerce for Standards and Technology and Acting Director 
This publication is available free of charge from: http://dx.doi.org/10.6028/NIST.GCR.14-977 
Disaster Resilience Workshop

National institute of Standards and Technology

Gaithersburg, MD

April 7, 2014

Meeting Summary

1. APRIL 7, 2014 NIST DISASTER RESILIENCE WORKSHOP AGENDA.................... 1

2. OPENING SESSION (8:00-8:45 A.M.).................................................................................... 2

3. MORNING GENERAL SESSION (8:45-9:30 A.M.) ………................................................. 5

4. MORNING BREAKOUT SESSION \#1: PERFORMANCE GOALS AND METRICS FOR COMMUNITY RESILIENCE (10:00-11:30 A.M.).................................................... 6

5. MORNING BREAKOUT SESSION \#2: IMPROVING COMMUNITY RECOVERY FROM A DISASTER (10:00-11:30 A.M.) ....................................................................... 8

6. MORNING BREAKOUT SESSION \#3: INTERDEPENDENCIES AMONG LIFELINES AND BUILDINGS (10:00-11:30 A.M.)..................................................... 10

7. MORNING BREAKOUT SESSION \#4: COMMUNITY IMPACTS OF DISASTER EVENTS (10:00-11:30 A.M.)

8. MORNING BREAKOUT SESSION \#5: LESSONS LEARNED FROM PAST DISASTERS (10:00-11:30 A.M.) .............................................................................................. 13

9. AFTERNOON GENERAL SESSION (1:00-1:45 P.M.) .................................................. 15

10. AFTERNOON BREAKOUT SESSION \#1: BUILDINGS AND FACILITIES (1:45-

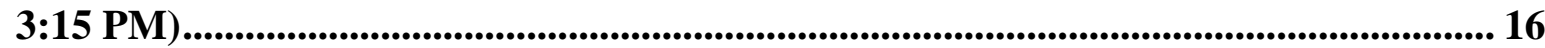

11. AFTERNOON BREAKOUT SESSION \#2: TRANSPORTATION SYSTEMS (1:453:15 PM). 17

12. AFTERNOON BREAKOUT SESSION \#3: POWER/ENERGY SYSTEMS (1:45-3:15 PM) 18

13. AFTERNOON BREAKOUT SESSION \#4: COMMUNICATION SYSTEMS (1:453:15 PM). 19

14. AFTERNOON BREAKOUT SESSION \#5: WATER AND WASTEWATER SYSTEMS (1:45-3:15 PM) 20 


\section{April 7, 2014 NIST Disaster Resilience Workshop Agenda}

The following is an agenda for the workshop that took place on April 7, 2014 at the National Institute of Standards and Technology (NIST) Gaithersburg Campus:

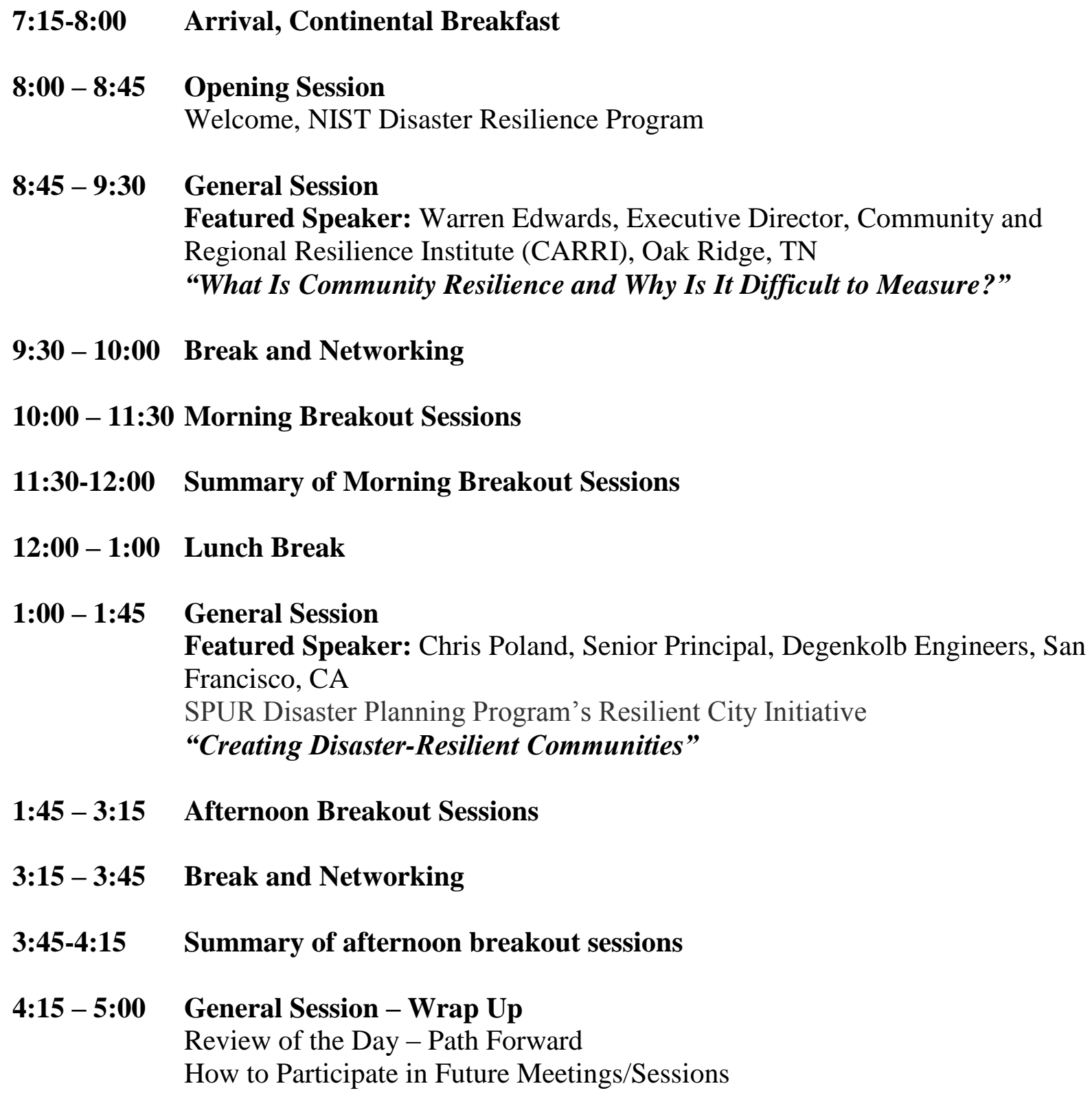




\section{Opening Session (8:00-8:45 a.m.)}

The opening session included remarks from Dr. Patrick Gallagher, Director of the National Institute of Standards and Technology and Under Secretary of Commerce for Standards and Technology. Here is a summary of his remarks:

In a country that lives with continuous hazards, it's imperative that we be ready to face those hazards for national and economic security. Unfortunately it often takes tragedy (Katrina, Joplin, Sandy) to make meaningful change. We, as a nation, are vulnerable to natural disasters. In 2011, there were 14 weather or climate-related events that each exceeded $\$ 1$ billion in damage and all together totaled $\$ 55$ billion in damages. Sandy alone caused more than $\$ 65$ billion in damage in 2012. This highlights the need to make communities more resilient to the effects of climate change as well as from natural and technological hazards.

Why has NIST been asked to lead this process to develop the framework and what is the framework? NIST has a history of activities like this. In the last few years, NIST has helped to assemble and encourage public-private collaboration in several emerging technology areas. NIST has a long history as a convener of technology experts in many different fields to help solve tough national challenges. This has been done for cloud computing, cyber security, Smart Grid interoperability, and a project on interoperability of cyber-physical systems currently underway. What is a framework? An operational framework definition is: Whatever it takes to get action across a community, including reference architecture, structures, supporting implementation guidelines, definitions, etc.

In the task we're facing today, why did we choose the framework approach? In any community, we're talking about systems of systems. In disaster resilience of a community, we're talking about a system that is made up of people, government, business, industry, as well as buildings and infrastructure lifelines. All of these need to function together and recover after an event. Whenever we find ourselves talking about complex systems, such as those present in a community, we have found the framework approach to be effective.

This workshop is the kickoff for the Disaster Resilience Framework. In order to be effective, this has to be your work. The concepts that we will identify in the framework are too dynamic to make a shelf document - it will be a living document. Disaster resilience will vary nationally, but we believe there is common ground that can be applied to every community.

This is the first of several meetings and framework work products. It should evolve into a self-governing process. We are working on a draft, and we are building a process that 
will keep going. Communities across the nation may have different challenges and best practices and a national guideline will be useful. International approaches can also be helpful. Thanks for joining us.

Dr. Gallagher's remarks were followed by remarks from Dr. Howard Harary, the NIST Engineering Laboratory Director. Here is a summary of Dr. Harary's remarks:

NIST has been involved in disasters and building safety since it was founded in 1901. Following the Baltimore Fire of 1904, where variations of fire hose couplings prevented other communities from helping with suppression, the importance of national standards for firefighting technologies and many other systems came to light. NIST provides research, support, and investigations to help advance standards and codes to enhance building performance and safety.

NIST research includes:

- $\quad$ Reducing the collapse risk of buildings.

- $\quad$ Reducing earthquake and fire hazards.

- Understanding wind hazards.

- Improving standards and developing a performance based approach.

Statutory responsibilities include the National Earthquake Hazard Reduction Program (NEHRP), the National Construction Safety Team Act (NCST), and the National Windstorm Impact Reduction Program (NWIRP). The World Trade Center Investigation and the Joplin Tornado Study are examples of investigations carried out under the NCST Act. Work conducted under NEHRP and NCST have led to significant improvements in building performance through increased understanding of how structures respond to hazards, as well as new codes and standards provisions based on this work.

Disaster resilience requires us to go further and consider how buildings and infrastructure can continue to perform their functions during and after a disaster. The role of these systems is crucial to providing shelter, basic services, financial and economic means, and the other attributes of modern life. Buildings and infrastructure lifelines within communities need to resist hazards and must regain function within a reasonable time. Otherwise, people move away, businesses leave, and economic recovery is significantly impacted. Disaster resilience, with a focus on community-based disaster resilience, is critical to a national solution.

We need to think about buildings and lifelines as a connected system of systems, as multidimensional systems. The framework will specifically focus on the role of building and infrastructure systems, existing codes and standards, and the gaps that must be addressed to enhance resilience. We will publish a draft framework for public comment in April 2015. The Framework will be updated on a regular basis as a living document. 
Finally, Mr. Stephen Cauffman, the Lead for the Disaster Resilience Program, gave a presentation summarizing the goals and development plan for the Disaster Resilience Framework. The slides from Mr. Cauffman's presentation can be found on the website where the workshop documents are archived at http://www.nist.gov/el/building_materials/resilience/workshop_documents.cfm or can be accessed directly from the following link:

http://www.nist.gov/el/building_materials/resilience/upload/Cauffman_April-7-DisasterResilience-Workshop-final.pdf 


\section{Morning General Session (8:45-9:30 a.m.)}

The featured speaker for the morning general session was Warren Edwards, the Executive Director of the Community Regional Resilience Institute (CARRI) in Oak Ridge, TN. The slides from Mr. Edward's presentation, entitled "What is Community Resilience and Why is it Difficult to Measure? " are stored on the website where the workshop documents are archived at http://www.nist.gov/el/building_materials/resilience/workshop_documents.cfm or can be accessed directly from the following link:

http://www.nist.gov/el/building_materials/resilience/upload/NIST-April-7-2014.pdf 


\section{Morning Breakout Session \#1: Performance Goals and Metrics for Community Resilience (10:00-11:30 a.m.)}

For the built environment, there was a focus on mitigation, performance/functionality, and recovery.

For a nominal community with homes, schools, businesses, manufacturing, healthcare, public safety services, power, communications, roads and bridges, and water and wastewater systems, the following questions were asked and discussed by the group:

Question 1: What are community and social needs during and after a disaster event? The group worked to summarize and prioritize the following needs:

- Before the disaster:

- Connectedness of neighborhood/family - getting the community to understand that it needs to be tied together (through training).

- Trustworthy multi-level leadership.

- Recovery planning for disasters.

- During the disaster:

○ Communicate information.

- Stability (order/government).

- Life safety survival needs - healthcare and life safety.

- After a disaster:

○ Jobs.

○ Schools.

- Meet social needs.

○ Hope for full recovery to keep community together.

Question 2: Based on the social needs, what are desirable community performance goals for the built environment?

A lively discussion was held within the group during this session, which was summarized with the following points:

- The time frame for restoration needs to be specific, tied to infrastructure, and change based on community.

- Performance goals differ by region - rural versus urban, reflect cultural fabric of a community.

- The value of the system is important (i.e., how much are you willing to pay for resilience?).

- It is important to organize resources at the community level. 
The community should be involved in scenario development (i.e., the probability of occurrence, how concerned, what would be impacted?) and an assessment of existing capability for different scenarios. We need to focus on creating additional capability/capacity required for full recovery. 


\section{Morning Breakout Session \#2: Improving Community Recovery from a Disaster (10:00-11:30 a.m.)}

Recovery is an extremely important part of resilience. Damage to a community during a hazard event is always a possibility, though the level of damage may vary. The following questions were asked and discussed by the group:

Question 1: What types of emergency plans are needed for a disaster event? The group discussed emergency plans and developed the following main points:

- Recovery and hazard mitigation planning needs work. Hazard mitigation plans should be updated quite a bit.

- Communication during planning and design needs to be improved.

- Emergency plans need to incorporate more science.

- Local community must be included in planning and crisis management.

- Need to think about all appropriate types of disasters, both short and long term (e.g., drought is an example of a much different type of disaster).

- Social needs, age groups, language barriers, etc. all need to be accounted for in planning, which will vary by region and community.

\section{Question 2: What type of recovery plans are needed for a disaster event?}

The group discussed recovery plans and summarized the needs as follows:

- Each community needs to complete a self-assessment to understand where its weaknesses are and where improvements can be made (i.e., define their vulnerabilities).

- The community should define the sequence of events in order to have an organized recovery after a disaster event.

- Plans developed must be concise and easily understood by the community.

- Need to clearly define recovery generated from resilience. Recovery is ultimately the end-product of a community's resilience.

Question 3: What are obstacles to rapid recovery of buildings and lifelines in communities? The group discussed and summarized the obstacles to rapid recovery as follows:

- Lack of prioritization by communities.

- Plan implementation, money, and political will.

- Lack of accurate inventory. There is a known capacity before an incident, but what about afterwards?

- Demographics (e.g., some areas of the U.S. have literacy rates akin to developing countries). 
- Lack of communication about plans in place, what is expected of people, resources available to people, and lack of training. 


\section{Morning Breakout Session \#3: Interdependencies among Lifelines and Buildings (10:00-11:30 a.m.)}

Buildings and other structures are not functional without lifelines, and recovery of one type of lifeline may be hampered if other lifelines are damaged. The following questions were asked and discussed by the group:

\section{Question 1: How do building and facility functions depend on lifelines?}

The group discussed how building and facility function depend on lifelines. The key points were summarized as follows:

- First, the framework needs to define lifelines because international reports have different definitions and it is better to make sure the readers understand the terminology correctly. The domestic definition includes water, power, communication, transportation, and access to health facilities.

- The broad way to look at lifelines is to look at examples from each sector (e.g., hospitals, residential, government, etc.) and determine what is needed to supply the required services. For example, a hospital needs functionality, including support services: pharmacy, laundry, food, and sanitation. Another example from Sandy is that there was no fuel at the pumps. Therefore, transportation was restricted and civilians could not get to hospitals.

- The critical factors were agreed to be water and power because you cannot occupy a home, school, etc. without it. Fuel can also be a big concern if everyone is relying on generators for power.

- Communication is important as it improves the speed of recovery for power and water.

- The level of service is an important consideration. After a disaster event, the lifelines do not need to be $100 \%$ operational as there should be time allowed to recover all loss of functionality. However, minimum levels of service should be established quickly so that buildings and facilities are functional.

\section{Question 2: What lifelines do we want to prioritize?}

Once the group discussed how buildings and facilities depended on lifelines, the group discussed prioritization of the lifelines:

- Prioritization will vary by region and community.

- Local customs and practices will have to be taken into account for prioritization.

- All institutions are dependent on lifelines; however, the question is to what degree the building/facility relies on each lifeline. 
- Must consider what role each facility plays in the community. Not every building/facility needs to be functional immediately after a disaster event. Therefore, need to identify critical facilities and establish priorities for bringing buildings/facilities back online.

- Fragility and redundancy of lifelines need to be addressed. 


\section{Morning Breakout Session \#4: Community Impacts of Disaster Events (10:00-11:30 a.m.)}

Damage to the built environment during natural hazard events can have long-lasting impacts. Significant or cascading damage effects can greatly increase the recovery time and further add to the community impacts. The following questions were asked and discussed by the group:

\section{Question 1: What is the best way to define resilience? Does resilience refer to a disaster, a disruption or both?}

The following key discussion points were summarized by the group:

- Resilience does not necessarily have to do with just extreme events, but also has to do with a major disruption.

- Cascading failures must be considered where one issue or multiple smaller issues can lead to a larger disaster.

- Events can happen immediately (over a short duration) or over time (e.g., earthquakes have a short duration without warning, whereas hurricanes last hours to days and communities typically have days to prepare for the storm).

- Public needs to have reasonable expectations.

The following questions were also raised by the group that should be considered in developing the resilience framework:

- What do we do about the existing, nonconforming construction as it pertains to resiliency?

- Can the marketplace force the raising of the level of performance required by standards?

- How do we manage perceived risk versus actual risk?

- System redundancy can have a mitigating effect, but what is the "sweet spot" of cost versus benefit?

- How often do we check if the redundancy of a system works?

- How do we verify redundancy?

- How do we verify consistency? 


\section{Morning Breakout Session \#5: Lessons Learned from Past Disasters (10:00-11:30 a.m.)}

Many best practices or changes to codes and standards are based on lessons learned during past disaster events. Lessons at the community level need to be identified. The following questions were asked and discussed by the group:

\section{Question 1: What was the disaster? What happened? What improvements could/have been} made?

A number of past disasters were discussed as well as their lessons learned during this breakout session. The following lists some of the disasters discussed and main lessons learned from them:

- $\quad$ World Trade Center - 9/11

○ Lessons Learned: Spread infrastructure out to limit impacts and have built-in redundancy, so as to avoid a situation where single point failures shut down an entire system (e.g., communications).

- Hurricane Katrina and Super-storm Sandy

○ Lessons Learned: Elevating backup equipment has been a recommendation for over 15 years. Changing the codes and standards is good, but incentive/drive needed to make changes is missing.

o Need a decision-making system to evaluate how to decide to spend money to get the best combination of results (mitigation versus maintenance cost after storm).

- Moore, OK tornadoes

- Moore, OK has been hit three times by tornadoes. Result is that they developed a local residential building code where the wind design speed is $135 \mathrm{mph}$ instead of $90 \mathrm{mph}$, per ASCE 7.

Question 2: What improvements could/have been made to emergency planning, constructed systems, and recovery plans?

The key improvements were summarized by the group as follows:

- Code incentives:

- Build to higher standards.

- Consider as-built versus as-designed.

- Consider existing versus new construction.

- Prevent additional damage seen in past disasters.

- Recovery plans:

○ Use lessons learned.

- Educate people.

- Evacuation planning. 
- Models of other disasters.

- Motivation on a local/personal level:

o Personal connections.

○ Educating the public.

- Relationship/trust building.

○ Risk construction. Why build here?

- Evaluation process/standards:

- System/decision-making process to rebuild.

- Evaluate performance.

- National level support:

- Funding and policy changes.

○ Include resilience requirements. 


\section{Afternoon General Session (1:00-1:45 p.m.)}

The featured speaker for the afternoon general session was Chris Poland, the former Chairman of Degenkolb Engineers and Co-Chair of the SPUR Disaster Planning Program's Resilient City Initiative. The slides from Mr. Poland's presentation, entitled "Creating Disaster-Resilient Communities" are stored on the website where the workshop documents are archived at http://www.nist.gov/el/building_materials/resilience/workshop_documents.cfm or can be accessed directly from the following link:

http://www.nist.gov/el/building_materials/resilience/upload/SF-Case-Study-in-Resilience.pdf 


\section{Afternoon Breakout Session \#1: Buildings and Facilities (1:45-3:15 pm)}

The current codes/standards are considered to be the minimum requirements and primarily address life safety. Community resilience also addresses minimizing loss of functionality, recovery time, and costs. For homes, businesses, critical facilities, manufacturing, etc., the following question was asked and discussed by the group:

\section{Question 1: What issues affect resilience that need to be addressed?}

The group discussed the issues affecting the resilience of buildings and facilities at length. The following are some of the main points that resulted from the discussion:

- Critical facilities need to look at the supply chain related to that facility.

- Since disasters are generally local, the solutions need to be local (i.e., defined and planned out at the community level).

- A broad framework would be very useful to support resiliency.

- Geography and demographics will play an important role in community planning and implementation of the framework at the local levels.

- Research is required to understand what people are already doing with regards to making improvements in resilience.

- A financial framework or financial element of the framework is needed to help develop incentives for resiliency so that communities are more interested in making their buildings and lifelines more resilient.

- Some form of definition needs to exist in order to communicate what resilience is and how to accomplish it (e.g., something similar to the LEED program with a tiered approach may be viable). LEED started small and focused and then grew to encompass more types of structures.

- For wind events, what your neighbor does is very important because wind-borne debris, collapse, etc. can affect your exposure to risk (i.e., what the community does impacts the individual and what the individual does impacts others in the community). 


\section{Afternoon Breakout Session \#2: Transportation Systems (1:45-3:15 pm)}

The current codes/standards are considered to be the minimum requirements and primarily address life safety. Community resilience also addresses minimizing loss of functionality, recovery time, and costs. For roads, bridges, airports, ports, railroads, etc., the following question was asked and discussed by the group:

\section{Question 1: What issues affect resilience that need to be addressed?}

The group discussed the issues affecting resilience that need to be addressed for transportation in detail, which include:

- Coastal flooding.

- Sea level rise.

- Weather.

- Lack of a detailed inventory of what is contained within the community.

- Debris removal (i.e., where do we put the debris? Where do we stage the repair materials?).

- Need to break-up transportation resiliency problems into parts: evacuation, soundness of infrastructure, nodes.

Roadblocks to implementing resiliency plans were also discussed and it was agreed that these included:

- Cost.

- Maintenance.

Other considerations regarding transportation systems included:

- The current transportation system is old and needs to be strengthened via replacement and upgrading of materials.

- Need to consider transportation systems as networks (i.e., need to think about the flow of the system, not just individual pieces). 


\section{Afternoon Breakout Session \#3: Power/Energy Systems (1:45-3:15 pm)}

The current codes/standards are considered to be the minimum requirements and primarily address life safety. Community resilience also addresses minimizing loss of functionality, recovery time, and costs. For generation, transmission, and distribution facilities, the following questions were asked and discussed by the group:

Question 1: What issues affect resilience that need to be addressed?

The group discussed the issues affecting resilience of the power/energy system, and identified the following main points:

- Utilities and state regulators would benefit from identifying areas within the electrical transmission/distribution system that are the weakest and cause the most power outages.

- Since the power system is changing, we need to look forward to the next 10-15 years, coupled with the idea that this is not governed by communities - the utilities and state regulators are governing.

- Biggest weaknesses are in the distribution system, which have little redundancy. Transmission systems also have vulnerabilities, but have a lot of redundancy to offset the vulnerabilities.

\section{Question 2: What are the inter-dependencies with other buildings or lifeline systems that} need to be considered?

The group identified the following inter-dependencies of other lifelines with power/energy systems:

- Need communication and transportation for any response to resolve power failures.

- Putting IT equipment into electric infrastructure has increased interdependency between communications and power sectors. Redundancy of both of these systems is needed to avoid failures.

- Communications drive the rest of the utilities. In the case of Hurricane Sandy, power and water utilities were denied access to their own assets to begin the recovery process, which goes back to communication. 


\section{Afternoon Breakout Session \#4: Communication Systems (1:45-3:15 pm)}

The current codes/standards are considered to be the minimum requirements and primarily address life safety. Community resilience also addresses minimizing loss of functionality, recovery time, and costs. For cellular, landline, and IT facilities, the following questions were asked and discussed by the group:

Question 1: What issues affect resilience that need to be addressed?

The group identified the following resilience issues as top priorities:

- Strength of communications systems in a multi-dimensional environment.

- Asset management (i.e., exercising, testing, training, etc.).

- Shift in method/mode of communication based on technology (i.e., look forward, not backward in planning process).

- Ensure that there is a Plan B, C, etc. in case the plan (e.g., response/recovery) does not work as intended.

- Need to consider time frame, hazard and expected importance in decision-making for resilience improvements and recovery and response planning.

\section{Question 2: What are the inter-dependencies with other buildings or lifeline systems that} need to be considered?

The group discussed interdependencies of other lifelines with communications systems and summarized the discussion as follows:

- Communications systems are dependent on power.

- Other lifelines (including buildings, transportation, water, law enforcement, security, etc.) are dependent on communication.

- Co-dependence was also discussed. For example, security and communications may have to be recovered simultaneously as security personnel want to be able to communicate with each other to secure an area, but communications personnel want the area to be secured before they enter to work.

- Financial aspects, prioritization and user dependence must also be considered. 


\section{Afternoon Breakout Session \#5: Water and Wastewater Systems (1:45- 3:15 pm)}

The current codes/standards are considered to be the minimum requirements and primarily address life safety. Community resilience also addresses minimizing loss of functionality, recovery time, and costs. For water and wastewater treatment facilities and pipelines, the following questions were asked and discussed by the group:

Question 1: What issues affect resilience that need to be addressed?

The group identified the following resilience issues for water and wastewater systems:

- Lack of redundancy.

- Prohibitive cost retrofitting.

- Plant ownership, investment capability, and willingness.

- Climate impacts (e.g., droughts, floods, sea level rise).

- Lack of primary and back-up emergency power for pumps.

- Politics and jurisdiction.

- Personnel for recovery.

- Using green infrastructure to build resilience.

- Lack of standards for pipeline design retrofit.

Question 2: What are the inter-dependencies with other buildings or lifeline systems that need to be considered?

Water and wastewater systems are a part of a complex overall system that must be evaluated as a whole to make improvements in resilience. The group discussed inter-dependency with other systems regarding the following:

- Inter-dependency with buildings.

○ Buildings are designed (typically) for 50 years, whereas infrastructure/lifelines are expected to have a longer service life. Communities should consider how to resolve the differences in their planned service periods.

○ Many buildings have built-in fire protection systems. In the event of a disaster, if there is no water, the suppression system will likely be non-functioning.

- Inter-dependency with transportation.

- Employees need to get to the plant and need to mobilize personnel and supplies to repair water and sewer mains.

- Inter-dependency with communications systems.

- Utility companies rely on cell phone communications to dispatch personnel.

- Inter-jurisdictional water supply.

○ Downstream jurisdictions will be impacted if the feeding jurisdiction is affected. 


\section{Question 3: What are the intra-dependencies that need to be considered?}

The group also discussed intra-dependencies within the water and wastewater system, which include:

- Facility versus distribution systems.

- Pumps offsite, booster systems, gravity only systems, and valves.

- Hundreds of miles of pipes resulting in a large area of potential problems to maintain and fix.

- Lab capability. If there is a failure, the community needs to know if the water is safe. 